2. Moore KP, Wong $F$, Gines $P$, et al. The management of ascites in cirrhosis: report on the consensus conference of the international ascites club. Hepatology 2003;38(1):258-66.

\section{P045 ATTENDANCE AT BI-ANNUAL HEPATOCELLULAR CANCER SURVEILLANCE, IN A HEPATITIS C CIRRHOSIS COHORT, - DOES DEPRIVATION MATTER?}

${ }^{1}$ Charlotte Morea*, ${ }^{2}$ Ryan Buchanan. ${ }^{1}$ University of Southampton, UK; ${ }^{2}$ University Hospital Southampton, UK

\subsection{6/gutjnl-2021-BASL.54}

Background Hepatitis C (HCV) cirrhosis confers a twenty-fold increased risk of developing hepatocellular carcinoma. ${ }^{1} \mathrm{Bi}$ - annual ultrasound surveillance is strongly recommended for these patients and has been shown to improve their survival. ${ }^{2}$

3 However, adherence to surveillance continues to be persistently low and this cohort continues to encounter barriers to surveillance. ${ }^{4} 5$

Aim Determine engagement of patients with HCV cirrhosis in bi-annual ultrasound surveillance, including any association with index of multiple deprivation (IMD). ${ }^{6}$

Method This is a retrospective cohort study of patients with cirrhosis identified by the Southampton HCV treatment service. Data pertaining to patient demographics and hepatology appointments was collected from electronic medical records. The cohort was grouped into the upper and lower five deciles of deprivation, stratifying geographical data by the IMD.

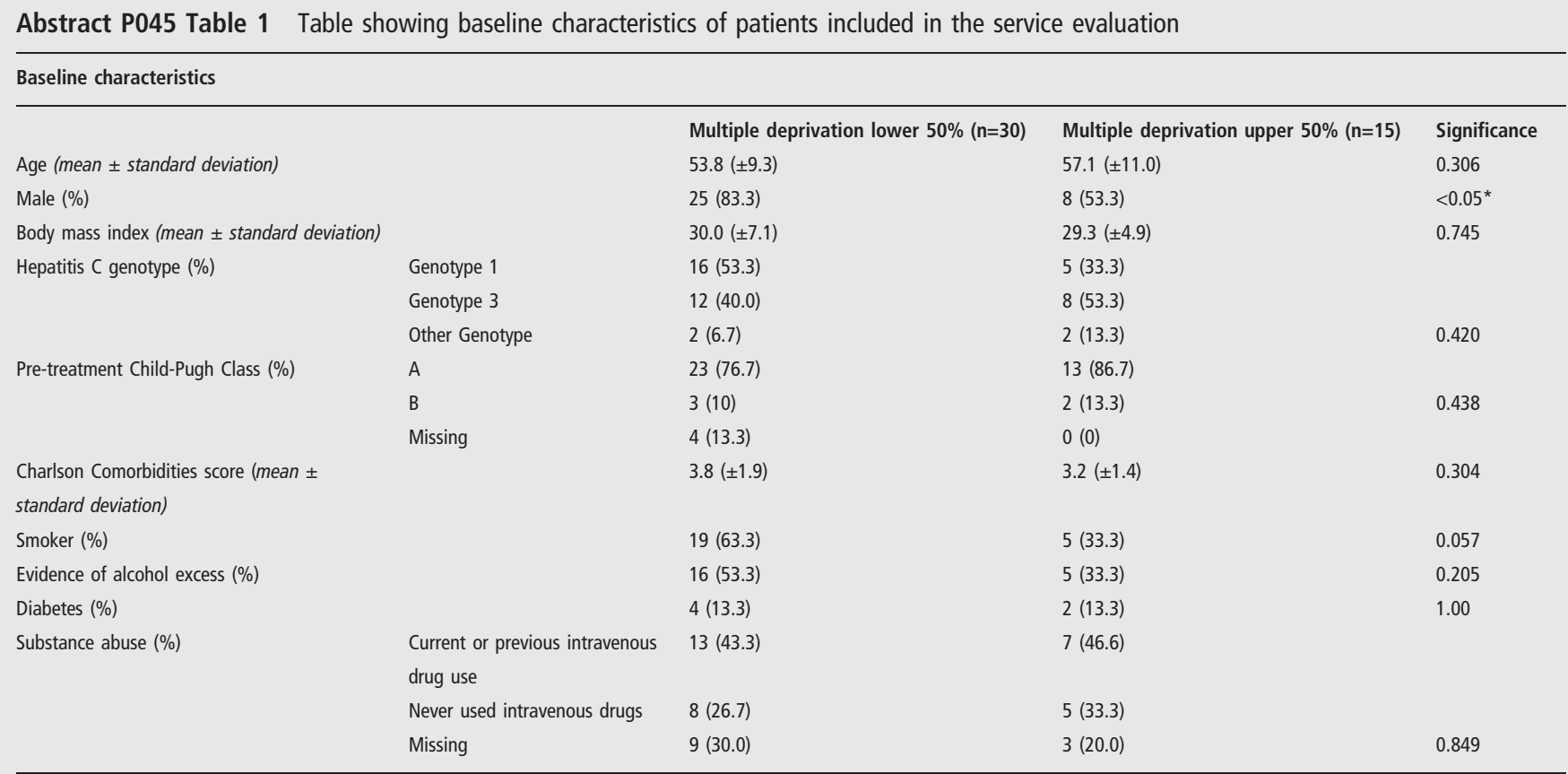

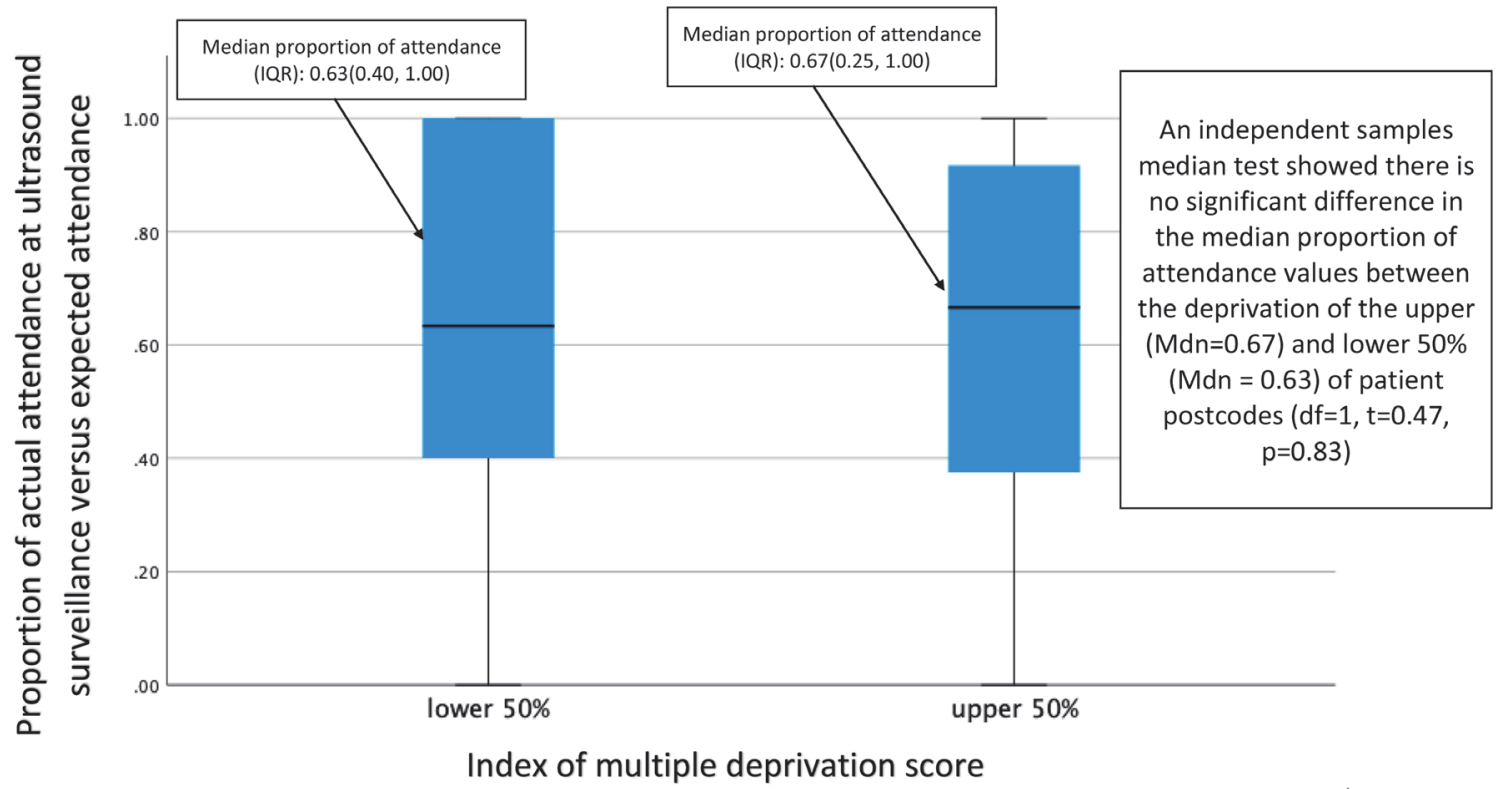

Abstract P045 Figure 1 A graph to show proportion of attendance stratified by patient postcode deprivation 
Engagement was measured as the proportion of actual ultrasound attendances versus number of expected ultrasound attendances. Descriptive analysis was done with SPSS version 27.

Results Our cohort was comprised of 45 patients (mean follow up of 2.34 years $(\mathrm{SD} \pm 357$ days)). In the more deprived $50 \%$ of the cohort there were significantly more males $\mathrm{X}^{2}((1, \mathrm{~N}=45)=4.60 \mathrm{p}=0.39)$, other baseline characteristics are reported in table 1 . The median cumulative rate of actual versus expected surveillance events across the cohort was $0.67(0.40,1.00)$. Figure 1 shows there was no significant difference in engagement between the less deprived groups $(0.63$ vs. $0.63 ; p=0.83)$. There was no significant association between outcomes dependant on IMD, 33/45 patients are under continued follow up, shown in chart 1.

Conclusion Engagement at this service is equivalent irrespective of IMD. Attendance rates at this service are comparable with the literature, demonstrating this services' ability to overcome barriers such as deprivation.

\section{REFERENCES}

1. Galle PR, Forner A, Llovet JM, et al. EASL clinical practice guidelines: management of hepatocellular carcinoma. Journal of Hepatology 2018;69(1):182-236.

2. Singal AG, Yopp A, S Skinner $C$, et al. Utilization of hepatocellular carcinoma surveillance among American patients: a systematic review. Journal of General Internal Medicine 2012;27(7):861-67.

3. Cross TJS, Villanueva A, Shetty $S$, et al. A national survey of the provision of ultrasound surveillance for the detection of hepatocellular carcinoma. Frontline Gastroenterol 2016;7(2):82-89. doi:10.1136/flgastro-2015-100617 (accessed 20th December 2020)

4. Waziry R, Hajarizadeh B, Grebely J, et al. Hepatocellular carcinoma risk following direct- acting antiviral HCV therapy: a systematic review, meta-analyses, and meta- regression. Journal of Hepatology 2017:67(6):1204-12.

5. Ministry of Housing, communities and Local government. English indices of multiple deprivation - postcode lookup. Available from: https://imd-by-postcode.opendatacommunities.org/imd/2019 [Accessed 15th May 2021]

\section{P046 LIVER RE-TRANSPLANTATION IN ADULTS; A SINGLE UK CENTRE EXPERIENCE (2009-2020)}

James Morgan*, Sara Mahgoub, Dhiraj Tripathi, Thamara Perera. University Hospitals Birrmingham, Birmingham, UK

\subsection{6/gutjnl-2021-BASL.55}

Liver transplantation is a life -saving modality for liver failure. Graft failure occurs in 5-22\% of all liver transplant recipients. ${ }^{1-6}$ Liver re-transplantation has been considered controversial, with clinical, economic, and ethical considerations. A study from Birmingham in 2009, reported no survival benefit following second and third re-transplantation. ${ }^{4} 6$

7 However, recent international data has suggested that survival following re-transplantation is comparable with first retransplantation. ${ }^{7}$ The data from one of the UK's largest liver transplant centres has been re-evaluated to provide contemporaneous knowledge to inform clinicians and assist with complex decision-making.

A retrospective study from January 2009 to March 2020. All adult patients who underwent first, second or third retransplantation during this study period at $\operatorname{xxxxxxxx}$ were included. Data collection included primary diagnosis requiring liver transplantation, aetiology of graft failure, donor and recipient factors and time interval between graft transplantation. Overall graft and patient survival rates were analysed with Kaplan-Meier curves.

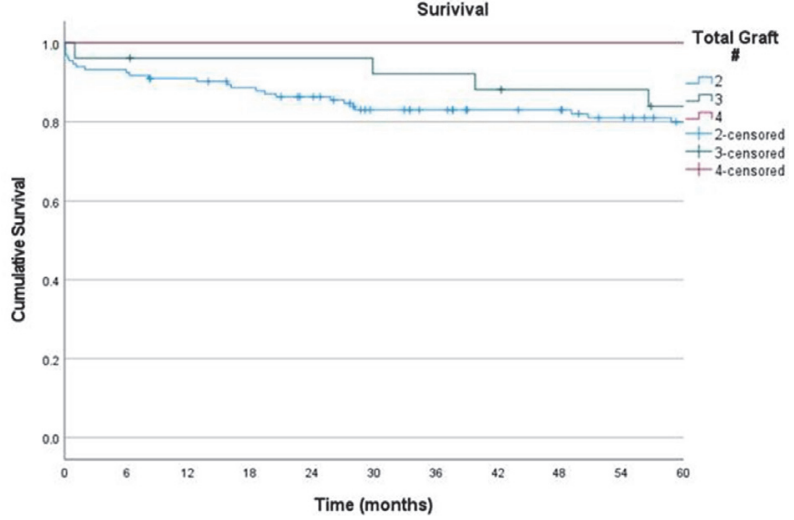

Abstract P046 Figure 1

There were 2454 adult and paediatric transplants during the study period. $6.6 \%$ (161) were re-transplanted, of which $15.5 \%$ (25) had a third retransplant and 1.2\% (2) a fourth. The commonest indication for initial transplant in those who were subsequently re-transplanted were: PSC (25.5\%), HCC (12.4\%), Seronegative (9.3\%) and PBC (9.3\%). 12.8\% of all grafts were DCD and $97.8 \%$ of these were used for initial transplant. Mean age at the time of first graft was 40 (range 0-68), second graft 44 (range 9-69) and third graft 33 (range 14-63). The most frequent reasons for re-transplantation were thrombotic and non-thrombotic graft infarction (28.7\%), biliary complications (20.7\%), early graft dysfunction (18.6\%), graft rejection $(17.5 \%)$ and recurrence of disease (14.9\%). Mean MELD score prior to 1st graft was 13, 2nd graft 21 and 3rd graft 22. Machine perfusion was utilised for 13 retransplants. Patient survival following 2 nd graft at 12, 24 and 60 months was 96\%, 86\% and $80 \%$ respectively. Patient survival following 3rd graft at 12, 24 and 60 months was 96\%, $96 \%$ and $84 \%$ respectively. Graft survival after 2 nd graft was $90 \%, 82 \%$ and $79 \%$ at 12,24 and 60 months, respectively. Graft survival after 3rd graft was $100 \%$ at 12, 24 and 60 months respectively.

Outcomes following re-transplantation have improved in the last 10 years despite increasing use of marginal donors. This could reflect careful patient selection, increased experience, and use of new technologies. Further study is suggested to identify specific factors influencing outcomes. Our findings support re-transplantation in carefully selected individuals

\section{REFERENCES}

1. Jain A, Reyes J, Kashyap R, Dodson SF, Demetris AJ, Ruppert K, et al. Long-term survival after liver transplantation in 4,000 consecutive patients at a single center Ann Surg 2000:232:490-500.

2. Busuttil RW, Farmer DG, Yersiz H, Hiatt JR, McDiarmid SV, Goldstein LI, et al. Analysis of long-term outcomes of 3200 liver transplantations over two decades: a single-center experience. Ann Surg 2005;241:905-16.

3. Adam R, McMaster P, O'Grady JG, Castaing D, Klempnauer JL, Jamieson N, et al. Evolution of liver transplantation in Europe: report of the European liver transplant registry. Liver Transp/ 2003;9:1231-43.

4. Marudanayagam R, Shanmugam V, Sandhu B, Gunson BK, Mirza DF, Mayer D, Buckels J, Bramhall SR. Liver retransplantation in adults: a single-centre, 25-year experience. HPB 2010;12(3):217-224

5. Takagi K, Domagala P, Porte RJ, Alwayn I, Metselaar HJ, van den Berg AP, Polak WG. Liver retransplantation in adult recipients: analysis of a 38-year experience in the Netherlands. Journal of Hepato-Biliary-Pancreatic Sciences 2020;27(1):26-33.

6. Jeffrey $A W$, Delriviere L, McCaughan $G$, Crawford M, Angus P, Jones R, Macdonald GA, Fawcett J, Wigg A, Chen J. Excellent contemporary graft survival for adult liver retransplantation: an Australian and New Zealand registry analysis from 1986 to 2017. Transplantation Direct 2019 Aug;5(8). 